Int. J. Electrochem. Sci., 14 (2019) $2391-2404$

\title{
Cavitation erosion behavior and surface morphology evolution of 316LN austenitic stainless steel in 3.5\% NaCl Solution
}

\author{
Zhisong Shao ${ }^{1}$, Shuaixing Wang ${ }^{1, *}$, Jia Kang ${ }^{1}$, Jijun Xin $^{2}$, Zheng $\mathrm{Li}^{1}, \mathrm{Nan} \mathrm{Du}^{1}$ \\ ${ }^{1}$ School of Material Science and Technology, Nanchang Hangkong University, Nanchang 330063, P. \\ R. China \\ ${ }^{2}$ Institute of Plasma Physics, Chinese Academy of Sciences, Hefei 230031, P. R.China \\ *E-mail: wsxxpg@126.com
}

doi: $10.20964 / 2019.03 .63$

Received: 7 October 2018 / Accepted: 28 December 2018 / Published: 7 February 2019

\begin{abstract}
The cavitation erosion experiments of $316 \mathrm{LN} \mathrm{SS}$ in $3.5 \mathrm{wt} \% \mathrm{NaCl}$ solution were done using an ultrasonic vibrator. The weight loss, surface roughness and surface morphology of 316LN SS at different cavitation erosion stages were analyzed by an analytical balance, roughness profiler, 3D video microscope and SEM. The cavitation erosion mechanism of 316LN SS was briefly discussed through the electrochemical testings when cavitation existed or not. In the cavitation erosion process of $316 \mathrm{LN} \mathrm{SS}$, the surface roughness increased linearly and then slowed down, but the cumulative weight loss and the mean corrosion depth hardly changed at initial stage and increased greatly hereafter. Under the continuous action of vacuolar collapse, grain boundaries of 316LN SS were preferentially dissolved, the pitting was simultaneously formed and then obvious peeling pits and cracks were finally present on the sample surface. Comparing to the static solutions, the corrosion current density of $316 \mathrm{LN} \mathrm{SS}$ in cavitation environments was bigger, and the passive zone was also narrower. That was to say, the cavitation erosion of 316LN SS was the synergetic effect process of cavitation mechanics and electrochemical corrosion. The cavitation effect promoted the occurrence of electrochemical corrosion, and the electrochemical corrosion further enhanced the role of cavitation mechanics.
\end{abstract}

Keywords: $316 \mathrm{LN}$ stainless steel; cavitation erosion; surface morphology; polarization curve

\section{$\underline{\text { FULL TEXT }}$}

(C) 2019 The Authors. Published by ESG (www.electrochemsci.org). This article is an open access article distributed under the terms and conditions of the Creative Commons Attribution license (http://creativecommons.org/licenses/by/4.0/). 